\title{
Influence of early colorectal cancer component on the positive margins after endoscopic resection: a retrospective study
}

Qing-Wei Zhang ${ }^{\dagger}$, Zi-Hao Dai ${ }^{\dagger}$, Xiao-Yi Wang, Yun-Jie Gao, Zhi-Zheng Ge* and Xiao-Bo Li*

\begin{abstract}
Background: Endoscopic treatment methods for early colorectal cancer (ECRC) mainly depend on the size and morphology. It is unclear whether different endoscopic resection methods could achieve curative resection for ECRC confined in the mucosa. The study was designed to compare the rate of positive vertical margin (VM) of ECRC with advanced adenomas (AAs) including adenoma $>1 \mathrm{~cm}$, villous adenoma, high-grade intraepithelial neoplasia/dysplasia stratified by different endoscopic resection methods.
\end{abstract}

Methods: Rate of positive VM for 489 ECRCs including Intramucosal (pTis) and superficial submucosal invasion (pT1) carcinomas were compared with those of 753 AAs stratified by different endoscopic resection methods using Chi-squared test. Multivariate logistic model was performed to investigate the risk factors of positive VM for different endoscopic resection methods.

Results: The pTis ECRC exhibited a similar rate of positive VM as that of AAs for en bloc hot snare polypectomy (HSP, $0 \%$ Vs. $0.85 \%, P=0.617$ ), endoscopic mucosal resection (EMR, $0.81 \%$ vs. $0.25 \%, P=0.375$ ) and endoscopic submucosal dissection (ESD, 1.82\% Vs. 1.02\%, $P=0.659$ ). The pTis carcinoma was not found to be a risk factor for positive VM by en bloc EMR $(P=0.349)$ or ESD $(P=0.368)$. The en bloc resection achieved for $p T 1$ a carcinomas exhibited similar to positive VM achieved through ESD (2.06\% Vs. 1.02\%, $P=1.000)$ for AAs. Nonetheless, EMR resulted in higher risk of positive VM (5.41\% Vs. $0.25 \%, P<0.001)$ for pT1a carcinomas as compared to AAs. The pT1a invasion was identified as a risk factor for positive VM in polyps with en bloc EMR (odds ratio $=23.90, P=0.005)$ but not ESD $(O R=2.96, P=0.396)$.

Conclusion: Collectively, the pTis carcinoma was not found to be a risk factor for positive VM resected by en bloc HSP, EMR or ESD. Additionally, ESD may be preferred over EMR for pT1 a carcinomas with lower rate of positive VM.

Keywords: Early colorectal cancer, Endoscopic submucosal dissection, Endoscopic mucosal resection, Hot snare polypectomy, Vertical margin

*Correspondence: zhizhengge@aliyun.com; lixb_1969@126.com ${ }^{\dagger}$ Qing-Wei Zhang and Zi-Hao Dai contributed equally to this work. Division of Gastroenterology and Hepatology, Key Laboratory of Gastroenterology and Hepatology, Ministry of Health, Renji Hospital, School of Medicine, Shanghai Jiao Tong University, Shanghai Institute of Digestive Disease, Shanghai, China

\section{Background}

Early colorectal cancer (ECRC) is defined as colorectal cancer (CRC) which has not invaded beyond submucosa regardless of lymph node metastasis (LNM). With increasing implementation of national CRC screening programs worldwide, more and more ECRCs are being diagnosed $[1,2]$ and endoscopically resected [3, 
4]. Owing to lower mortality and morbidity, endoscopic resection (ER), including polypectomy, endoscopic mucosal resection (EMR), endoscopic submucosal dissection (ESD), are more attractive to patients with ECRC as compared to surgery [5].

According to the European [6], US [7] and Japanese [8] guidelines for the management of colorectal cancers, endoscopic modalities, including polypectomy, EMR and ESD, are all eligible for resection of polyps. Even with pT1 staging, there is guarantee of complete resection and histologically confirmed low risk of lymph node metastasis (LNM). Complete resection is defined as en bloc the resection with negative horizontal margin (HM) and vertical margin (VM) for colorectal polyps. While positive $\mathrm{HM}$ is determined, endoscopic surveillance needs to be performed for 6 months owing to increased risk of local recurrence [8]. Furthermore, in patients with vertical noncurative resection, additional surgery should be done $[8,9]$.

According to the Japanese guideline, the choice of endoscopic modalities for colorectal cancers is based on the information of different parameters which include the size, morphology of the tumor and predicted depth of invasion $[8,10]$. Although most of the endoscopic modalities are chosen depending on the first two parameters mentioned above, only a few studies have investigated whether the depth of ECRC invasion is the risk factor for positive margins of lesions resected by en bloc ER.

Given this background, the present study was designed to evaluate whether intramucosal ECRC or submucosal invasion in polyps contribute to higher risk of positive $\mathrm{HM}$ or VM as compared with advanced adenomas (AAs), identified as precancerous lesions, by different en bloc ER methods.

\section{Methods}

\section{Patients}

In this study, patients with histologically confirmed adenomas with more extensive villous architecture, high-grade intraepithelial neoplasia/dysplasia, well or moderately differentiated adenocarcinoma with intramucosal (pTis) or submucosal (pT1) staging undergoing ER in the Renji Hospital from June 2008 to June 2019 were included. The exclusion criteria followed for the patients include: 1) Final pathology of lesion was diagnosed as squamous cell carcinoma or carcinoid tumor; 2) patients had familial adenomatous polyposis; 3) patients were diagnosed with inflammatory bowel disease; 4) patients had synchronous advanced CRCs.

The primary outcomes were rates of positive VM and positive HM by different en bloc endoscopic resection methods and the relevant risk factors.
Informed written consent was sought from the patients before the ER of colorectal polyps. This study was approved by the institutional review board (July 2019) at the Renji Hospital. The study protocol conforms to the ethical guidelines of the 1975 Declaration of Helsinki as reflected in a priori approval by the institution's human research committee.

\section{Variable and histopathological evaluation}

The endoscopic resection methods used in the present included HSP, EMR and ESD. The colorectum was subdivided into the proximal colon (cecum, ascending colon and transverse colon), the distal colon (descending colon and sigmoid) and the rectum (rectosigmoid).

All the specimens were sectioned serially at $2-3 \mathrm{~mm}$ intervals and subsequently stained with hematoxylineosin. The sections were then examined by experienced pathologists. The tumor size, histological type, HM, $\mathrm{VM}$, invasion depth and lymphovascular invasion (LVI) was determined for each specimen. The tumor size was defined as the largest diameter of the lesion. Histological diagnoses was based on the World Health Organization criteria [11] and Japanese Research Society for Cancer of the Colon and Rectum (JSCCR) classification [12]. The tumors were classified as advanced adenomas (AAs) and adenocarcinoma. In this study, AAs were defined as adenomas $>1 \mathrm{~cm}$, with more extensive villous architecture, or high-grade intraepithelial neoplasia/dysplasia. Adenocarcinoma was then classified as pTis or pT1 staging. Depth of the submucosal invasion was measured as per the JSCCR guidelines [8]. The tumors with pT1 staging were sub-classified as pT1a (less than $1000 \mu \mathrm{m}$ from the muscularis mucosae) and $\mathrm{pT} 1 \mathrm{~b}(1000 \mu \mathrm{m}$ more from muscularis mucosae). When the vertical margin of resected specimen was positive, the invasion depth was re-evaluated by histological examination of the specimen from additional surgery. Positive LVI was defined as the presence of cancer cells within the endothelial-line channels [13] and the En bloc resection was defined as a complete, single resection of the entire lesion.

\section{Statistical analysis}

For descriptive statistics, the absolute number with proportion for categorical variable, mean and standard deviation (SD) or median and interquartile range (IQR) for continuous variable were used, respectively. The chisquare test for categorical variable, Student's t-test or nonparametric Kruskal-Wallis rank sum test for continuous variable were used for comparisons among different patient groups, respectively. Multivariate logistic regression was performed using multivariate logistic regression model to identify the independent risk factor for outcomes of interest. Statistical analyses were performed by 
using R software package (version R-3.5.0, the R Foundation for statistical computing). A $P$ value $<0.05$ was taken as the measure of statistically significant difference.

\section{Results}

\section{Clinical characteristics of the patients and lesions}

A total of 1202 colorectal polyps from 1109 patients were included in the present study, including 753 (60.63\%) AAs and 489 (39.37\%) ECRCs. The number of polyps for HSP, EMR and ESD were 167 (13.45\%), 735 (59.18\%) and $340(27.38 \%)$, respectively (Table 1$)$.
With respect to the rates of en bloc resection, HSP (91.34\%) and ESD (93.81\%) were higher than EMR (89.47\%). According to the histological type, polyps from EMR $(307,41.77 \%)$ or ESD (139, 40.88\%) had higher percentage of ECRC as compared to polyps from HSP (43, 25.75\%). Additionally, the percentage of pT1 ECRC in polyps from EMR $(159,21.63 \%)$ or $\operatorname{ESD}(78,22.94 \%)$ was also higher as compared to polyps from HSP (14, $8.38 \%$ ). No significant difference was observed for LVI status, positive HM, positive VM among different endoscopic resection methods. The colorectal polyps resected by ESD tended to be sessile and larger. The detailed

Table 1 Clinical characteristics of the colorectal polyps as per different endoscopic resection methods

\begin{tabular}{|c|c|c|c|c|c|}
\hline \multirow[t]{2}{*}{ Characteristics } & \multirow{2}{*}{$\begin{array}{l}\text { All } \\
1202(100 \%)\end{array}$} & \multirow{2}{*}{$\begin{array}{l}\text { HSP } \\
167(13.89 \%)\end{array}$} & \multirow{2}{*}{$\begin{array}{l}\text { EMR } \\
712(59.23 \%)\end{array}$} & \multirow{2}{*}{$\begin{array}{l}\text { ESD } \\
323(26.87 \%)\end{array}$} & \multirow[t]{2}{*}{$P$} \\
\hline & & & & & \\
\hline Age, year (Median, IQR) & $63(56,68)$ & $62(57,67)$ & $63(56,68)$ & $64(57,69)$ & 0.211 \\
\hline Sex & & & & & 0.003 \\
\hline Female & 437(36.36\%) & $62(37.13 \%)$ & $233(32.72 \%)$ & $142(43.96 \%)$ & \\
\hline Male & $765(63.64 \%)$ & $105(62.87 \%)$ & $479(67.28 \%)$ & $181(56.04 \%)$ & \\
\hline Morphology & & & & & $<0.001$ \\
\hline Sessile & $474(39.43)$ & $39(23.35)$ & 215(30.2) & $220(68.11)$ & \\
\hline Pedunculated & $728(60.57)$ & $128(76.65)$ & 497(69.8) & 103(31.89) & \\
\hline Location & & & & & $<0.001$ \\
\hline Rectum & $347(28.87)$ & $48(28.74)$ & 195(27.39) & 104(32.2) & \\
\hline Distal colon & $594(49.42)$ & $82(49.1)$ & $392(55.06)$ & $120(37.15)$ & \\
\hline Proximal colon & $261(21.71)$ & $37(22.16)$ & $125(17.56)$ & $99(30.65)$ & \\
\hline Size $(\mathrm{cm})$ & & & & & $<0.001$ \\
\hline$\leq 1 \mathrm{~cm}$ & $355(29.53)$ & $96(57.49)$ & $245(34.41)$ & $14(4.33)$ & \\
\hline$\leq 2 \mathrm{~cm}$ & 498(41.43) & $57(34.13)$ & $366(51.4)$ & $75(23.22)$ & \\
\hline$>2 \mathrm{~cm}$ & $349(29.03)$ & $14(8.38)$ & 101(14.19) & $234(72.45)$ & \\
\hline Histology and invasion depth & & & & & 0.015 \\
\hline $\mathrm{AA}$ & $753(62.65)$ & $124(74.25)$ & $428(60.11)$ & $201(62.23)$ & \\
\hline pTis & 238(19.8) & 29(17.37) & 148(20.79) & 61(18.89) & \\
\hline pT1a & 131(10.9) & $6(3.59)$ & $86(12.08)$ & $39(12.07)$ & \\
\hline pT1b & $80(6.66)$ & $8(4.79)$ & $50(7.02)$ & $22(6.81)$ & \\
\hline LVI & & & & & 0.455 \\
\hline No & $1171(97.42)$ & 165(98.8) & 693(97.33) & 313(96.9) & \\
\hline Yes & $31(2.58)$ & $2(1.2)$ & $19(2.67)$ & $10(3.1)$ & \\
\hline En bloc resection & & & & & 0.012 \\
\hline Yes & 1099(91.43) & $159(95.21)$ & $637(89.47)$ & 303(93.81) & \\
\hline No & $103(8.57)$ & $8(4.79)$ & $75(10.53)$ & $20(6.19)$ & \\
\hline Positive HM & & & & & 0.682 \\
\hline No & 1167(97.09) & 164(98.2) & 689(96.77) & $314(97.21)$ & \\
\hline Yes & $35(2.91)$ & $3(1.8)$ & $23(3.23)$ & $9(2.79)$ & \\
\hline Positive VM & & & & & 0.582 \\
\hline No & 1156(96.17) & 163(97.6) & 683(95.93) & 310(95.98) & \\
\hline Yes & $46(3.83)$ & $4(2.4)$ & $29(4.07)$ & $13(4.02)$ & \\
\hline
\end{tabular}

HSP Hot snare polypectomy, EMR Endoscopic mucosal resection, ESD Endoscopic submucosal dissection, IQR Interquartile range, $A A$ Advanced adenoma, ECRC Early colorectal cancer, $p$ Tis Intramucosal, pT1a Submucosal invasion with less than 1000 um from the muscularis mucosae, $p T 1 b$ Submucosal invasion with 1000 um more from muscularis mucosae, LVI Lymphovascular invasion, HM Horizontal margin, VM Vertical margin 
clinicopathological characteristics are shown in the Table 1.

\section{Positive margins for polyps with different histology undergoing en bloc HSP resection}

For polyps undergoing en bloc HSP (Table 2), ECRC and AAs exhibited similar positive VM $(2.38 \%$ Vs. $0.85 \%$, $P=0.464)$ and positive HM ( $2.38 \%$ Vs. $0.85 \%, \mathrm{P}=0.464)$. In the multivariate logistic model with inclusion of potential risk factors for positive VM and $\mathrm{HM}$, including morphology, location, size, invasion depth and LVI, pT1b invasion $(\mathrm{OR}=14.88,0.64-343.43, P=0.092)$ may have insignificant influence on both of the results.

\section{Positive margins for polyps with different histology undergoing en bloc EMR resection}

Concerning polyps en bloc resected by EMR (Table 2), ECRC components in polyps showed higher risk of positive VM $(5.51 \%$ Vs. $0.25 \%, P<0.001)$ but not HM $(2.54 \%$ Vs. $1.25 \%, P=0.345)$ as compared to AAs. However, it was found that pT1 ECRCs $(10.62 \%, P<0.001)$ including pT1a $(5.41 \%, P<0.001)$ and pT1b $(20.51 \%, P<0.001)$ but not pTis ECRCs $(0.81 \%, P=0.416)$ exhibited higher risk of positive VM for lesions as compared to AAs (Table 2). These findings were also validated by the multivariate logistic models. The rectum location $(\mathrm{OR}=5.62$, $1.19-26.51, P=0.029)$, ECRC $\mathrm{pT} 1 \mathrm{a}$ invasion $(\mathrm{OR}=23.90$, 2.55-223.76, $P=0.005)$, pT1b invasion $(\mathrm{OR}=111.84$, $1.96-1045.55, P<0.001)$ compared to AAs were independent risk factors for positive VM (Table 3). However, none of the risk factors were found for positive HM resection (Table 4).

Positive margins for polyps with different histology undergoing en bloc ESD resection

With respect to polyps undergoing en bloc ESD (Table 2), the ECRC components in polyps exhibited higher risk of positive VM (4.72\% Vs. $1.02 \%, P=0.041)$ but not positive HM $(2.83 \%$ Vs. $2.03 \%, P=0.659)$ to AAs. Further subgroup analyses (Table 2) revealed pT1 ECRC $(7.84 \%$, $P=0.005)$, pT1b $(18.75 \%, P<0.001)$ but not pT1a $(2.86 \%$, $P=0.374)$ or pTis ECRC $(1.82 \%, P=0.627)$ to exhibit higher risk of positive VM as compared to AAs. The multivariate logistic models only identified pT1b invasion ( $\mathrm{OR}=142.87,7.82-2803.00, P=0.001)$ as independent risk factors for positive $\mathrm{VM}$ as compared to AAs (Table 3). Moreover, multivariate logistic regression also found $\mathrm{pT} 1 \mathrm{~b}$ invasion $(\mathrm{OR}=35.55,1.44-879.44$, $P=0.029)$ to be an independent risk factor for positive HM in polyps with en bloc ESD (Table 4).

\section{Discussion}

To the best of our knowledge, present study for the first time investigates whether depth of invasion of ECRC contributes to the higher risk of positive VM or HM after different en bloc ER. The present study demonstrated that pTis ECRC did not contribute to risk of positive VM or HM irrespective of endoscopic resection methods. The multivariate regression model identified pT1a invasion and $\mathrm{pT} 1 \mathrm{~b}$ invasion as independent risk factors for the positive VM in patients undergoing en bloc EMR. When en bloc resection was achieved, ESD showed similar curative vertical resection for $\mathrm{pT} 1 \mathrm{a}$ to AAs.

Usually, HSP is applied for the resection of small or pedunculated polyps $[14,15]$, which coincides with lesions resected by HSP in the present study. It has been reported that muscularis mucosa could be obtained as high as $96 \%$ and obtaining of submucosal tissue could be achieved as high as $81 \%$ in polyps resected by HSP [16], suggestive of applicability of HSP for resection of pTis or even pT1 carcinoma. In the present study, complete resection for all pTis carcinomas was achieved by en bloc HSP and comparable curative vertical and horizontal resection rate between AAs and ECRC was confirmed,

Table 2 Comparison of short outcomes for lesions subjected to en bloc HSP, EMR or ESD

\begin{tabular}{|c|c|c|c|c|c|c|c|c|c|}
\hline & \multicolumn{3}{|c|}{ Number of lesions } & \multicolumn{3}{|c|}{ Positive VM } & \multicolumn{3}{|c|}{ Positive HM } \\
\hline & HSP & EMR & ESD & HSP & EMR & ESD & HSP & EMR & ESD \\
\hline Overall & 159 & 637 & 303 & $2(1.26 \%)$ & $14(2.20 \%)$ & $7(2.31 \%)$ & $2(1.26 \%)$ & $11(1.73 \%)$ & $7(2.31 \%)$ \\
\hline AA & 117 & 401 & 197 & $1(0.85 \%)$ & $1(0.25 \%)$ & $2(1.02 \%)$ & $1(0.85 \%)$ & $5(1.25 \%)$ & $4(2.03 \%)$ \\
\hline ECRC & 42 & 236 & 106 & $1(2.38 \%)$ & $13(5.51 \%)$ & $5(4.72 \%)$ & $1(2.38 \%)$ & $6(2.54 \%)$ & $3(2.83 \%)$ \\
\hline pTis & 29 & 123 & 55 & $0(0 \%)$ & $1(0.81 \%)$ & $1(1.81 \%)$ & $0(0 \%)$ & $1(0.81 \%)$ & $1(1.81 \%)$ \\
\hline pT1 & 13 & 113 & 51 & $1(7.69 \%)$ & $12(10.62 \%)$ & $4(7.84 \%)$ & $1(7.69 \%)$ & $5(4.42 \%)$ & $2(3.92 \%)$ \\
\hline pT1a & 6 & 74 & 35 & $0(0 \%)$ & $4(5.41 \%)$ & $1(2.86 \%)$ & $0(0 \%)$ & $3(4.05 \%)$ & $1(2.86 \%)$ \\
\hline pT1b & 7 & 39 & 16 & $1(14.29 \%)$ & $8(20.51 \%)$ & $3(18.75 \%)$ & $1(14.29 \%)$ & $2(5.13 \%)$ & $1(6.25 \%)$ \\
\hline
\end{tabular}

HSP Hot snare polypectomy, EMR Endoscopic mucosal resection, ESD Endoscopic submucosal dissection, AA Advanced adenoma, ECRC Early colorectal cancer, $p$ Tis Intramucosal, pT1a Submucosal invasion with less than 1000 um from the muscularis mucosae, pT1b Submucosal invasion with 1000 um more from muscularis mucosae, $H M$ Horizontal margin, VM Vertical margin 
Table 3 The multivariate logistic regression analysis of risk factors for positive VM en bloc resected by HSP, EMR or ESD

\begin{tabular}{|c|c|c|c|c|c|c|c|c|c|}
\hline & \multicolumn{9}{|c|}{ Positive VM } \\
\hline & \multicolumn{3}{|l|}{ HSP } & \multicolumn{3}{|l|}{ EMR } & \multicolumn{3}{|l|}{ ESD } \\
\hline & OR & $95 \% \mathrm{Cl}$ & $P$ & OR & $95 \% \mathrm{Cl}$ & $P$ & OR & $95 \% \mathrm{Cl}$ & $P$ \\
\hline \multicolumn{10}{|l|}{ Size } \\
\hline$\leq 1 \mathrm{~cm}$ & Ref & & & Ref & & & Ref & & \\
\hline$\leq 2 \mathrm{~cm}$ & 2.12 & $0.04-125.82$ & 0.719 & 0.40 & $0.10-1.56$ & 0.185 & 0.68 & - & 1.000 \\
\hline$>2 \mathrm{~cm}$ & 0.00 & - & 0.998 & 0.43 & $0.06-3.08$ & 0.401 & 0.00 & - & 0.998 \\
\hline \multicolumn{10}{|l|}{ Morphology } \\
\hline Sessile & Ref & & & Ref & & & Ref & & \\
\hline Pedunculated & 0.16 & $0.00-7.89$ & 0.36 & 0.79 & $0.21-3.01$ & 0.732 & 0.26 & $0.02-3.47$ & 0.307 \\
\hline \multicolumn{10}{|l|}{ Location } \\
\hline Proximal colon & Ref & & & Ref & & & Ref & & \\
\hline Distal colon & 0.00 & - & 0.997 & 1.4 & $0.13-15.40$ & 0.785 & 10.84 & $0.46-253.85$ & 0.139 \\
\hline Rectum & 2.10 & $0.08-55.64$ & 0.656 & 5.62 & $1.19-26.51$ & 0.029 & 2.67 & $0.18-39.06$ & 0.473 \\
\hline \multicolumn{10}{|c|}{ Histology and invasion depth } \\
\hline AA & Ref & & & Ref & & & Ref & & \\
\hline ECRC pTis & 0.00 & - & 0.997 & 3.99 & $0.24-65.83$ & 0.333 & 3.18 & $0.26-39.60$ & 0.369 \\
\hline ECRC pT1a & 0.00 & - & 0.999 & 23.90 & $2.55-223.76$ & 0.005 & 2.96 & $0.24-36.43$ & 0.396 \\
\hline ECRC pT1b & 14.88 & $0.64-343.43$ & 0.092 & 111.84 & $1.96-1045.55$ & $<0.001$ & 142.87 & $7.82-2803.00$ & 0.001 \\
\hline \multicolumn{10}{|l|}{ LVI } \\
\hline negative & Ref & & & Ref & & & Ref & & \\
\hline positive & 0.67 & - & 1.000 & 3.66 & $0.56-23.89$ & 0.175 & 1.12 & $0.05-23.52$ & 0.942 \\
\hline
\end{tabular}

VM Vertical margin, HSP Hot snare polypectomy, EMR Endoscopic mucosal resection, ESD Endoscopic submucosal dissection, $A A$ Advanced adenoma; ECRC: early colorectal cancer, $p$ Tis Intramucosal, pT1a Submucosal invasion with less than 1000 um from the muscularis mucosae, $p T 1 b$ Submucosal invasion with 1000 um more from muscularis mucosae, LVI Lympovascular invasion

though only 13 pT1 lesions were included for the analysis. A previous study has reported that $\mathrm{CRC}$ to be detectable in $0.46 \%$ of polyps sized $\leq 5 \mathrm{~mm}$ in diameter and $3.3 \%$ of polyps with a diameter of $6-9 \mathrm{~mm}$ and that submucosal invasive cancer is as rare as $0.1 \%$ in small polyps [17]. Therefore, it may be safe to resect most of the small polyps by HSP under the premise of en bloc resection. However, close endoscopic observation should be carried out to suspected pT1 carcinomas in small polyps and HSP resection needs to be performed prudently since $19 \%$ of submucosal tissue for polyps by HSP could not be obtained and $14.29 \%(1 / 13)$ polyp was resected with positive $\mathrm{VM}$ and $\mathrm{HM}$ in the present study.

The EMR has been shown to achieve as high as $92 \%$ (105/114) of submucosa obtaining [18], which was consistent with the results of the present study that no difference in positive VM rate was observed between AAs and pTis ECRCs after en bloc resection. Similar results were observed in polyps with en bloc ESD, indicative of no influence of pTis ECRC on the positive VM irrespective of resection methods. Therefore, it may be reasonable to choose HSP, EMR and ESD based on the information available on the size and morphology of the tumor to resect pTis ECRCs [8] and there is no need to use more aggressive resection methods for polyps with pTis ECRC if en bloc resection could be guaranteed.

We further analyzed whether EMR was suitable for resection of pT1 ECRCs. pT1a invasion and pT1b invasion were found to be independent risk factors for positive VM with en bloc EMR. A previous study has reported that the median resection depth from muscularis mucosae was $338 \mu \mathrm{m}$ in EMR resection, though 92\% of submucosa could be obtained [19]. This indicated that some cases of pT1 ECRCs could not be resected for negative VM due to its limited resection depth. In the present study, $10.62 \%$ of positive VM could be observed in pT1 ECRCs with en bloc EMR. In contrary, as low as 2.86\% of positive VM for pT1a ECRCs were achieved for ESD when en bloc resection was achieved. The results of multivariate logistic regression models did not identify pT1a invasion as an independent risk factor for positive VM in polyps with en bloc ESD. Since en bloc EMR not ESD resulted in higher rate of positive VM for pT1a carcinomas as compared to AAs, ESD may be preferred over EMR for pT1a carcinomas. Consistently, pT1a ECRC is an indication for ESD according to the Japan Gastroenterological Endoscopy Society (JGES) guideline [18]. However, pT1a should be carefully differentiated from 
Table 4 The multivariate logistic regression analysis of risk factors for positive HM en bloc resected by HSP, EMR or ESD

\begin{tabular}{|c|c|c|c|c|c|c|c|c|c|}
\hline & \multicolumn{9}{|c|}{ Positive HM } \\
\hline & \multicolumn{3}{|l|}{ HSP } & \multicolumn{3}{|l|}{ EMR } & \multicolumn{3}{|l|}{ ESD } \\
\hline & OR & $95 \% \mathrm{Cl}$ & $P$ & OR & $95 \% \mathrm{Cl}$ & $P$ & OR & $95 \% \mathrm{Cl}$ & $P$ \\
\hline \multicolumn{10}{|l|}{ Size } \\
\hline$\leq 1 \mathrm{~cm}$ & Ref & & & Ref & & & Ref & & \\
\hline$\leq 2 \mathrm{~cm}$ & 2.12 & $0.04-125.82$ & 0.719 & 1.27 & $0.34-4.77$ & 0.719 & 0.52 & - & 1.000 \\
\hline$>2 \mathrm{~cm}$ & 0.00 & - & 0.998 & 0.00 & - & 0.993 & 0.00 & - & 0.998 \\
\hline \multicolumn{10}{|l|}{ Morphology } \\
\hline Sessile & Ref & & & Ref & & & Ref & & \\
\hline Pedunculated & 0.16 & $0.00-7.89$ & 0.36 & 0.53 & $0.15-1.91$ & 0.331 & 0.68 & $0.07-6.92$ & 0.738 \\
\hline \multicolumn{10}{|l|}{ Location } \\
\hline Proximal colon & Ref & & & Ref & & & Ref & & \\
\hline Distal colon & 0.00 & - & 0.997 & 0.00 & - & 0.992 & 0.00 & - & 0.994 \\
\hline Rectum & 2.10 & $0.08-55.64$ & 0.656 & 2.71 & $0.73-10.06$ & 0.136 & 0.00 & - & 0.994 \\
\hline \multicolumn{10}{|c|}{ Histology and invasion depth } \\
\hline AA & Ref & & & Ref & & & Ref & & \\
\hline ECRC pTis & 0.00 & - & 0.997 & 0.62 & $0.07-5.52$ & 0.67 & 1.67 & $0.17-16.74$ & 0.661 \\
\hline ECRC pT1a & 0.00 & - & 0.999 & 3.18 & $0.71-14.14$ & 0.129 & 1.49 & $0.15-14.90$ & 0.732 \\
\hline ECRC pT1b & 14.88 & $0.64-343.43$ & 0.092 & 3.36 & $0.50-22.75$ & 0.213 & 35.55 & $1.44-879.44$ & 0.029 \\
\hline \multicolumn{10}{|l|}{ LVI } \\
\hline negative & Ref & & & Ref & & & Ref & & \\
\hline positive & 0.67 & - & 1.000 & 2.42 & $0.19-30.28$ & 0.494 & 0.00 & - & 0.998 \\
\hline
\end{tabular}

HM Horizontal margin, HSP Hot snare polypectomy, EMR Endoscopic mucosal resection, ESD Endoscopic submucosal dissection, $A A$ Advanced adenoma, ECRC Early colorectal cancer, $p$ Tis Intramucosal, pT1a Submucosal invasion with less than 1000 um from the muscularis mucosae, $p T 1 b$ Submucosal invasion with 1000 um more from muscularis mucosae, LVI Lympovascular invasion

pT1b and the latter should be sent for surgery. In the present study, 80 pT1b (16.95\%) ECRCs were misdiagnosed as pTis or pT1a ECRCs and underwent endoscopic resection, which indicated a need for extra caution during the diagnosis of endoscopically curable ECRCs by the application of magnifying endoscopy [20].

The present study suffers from several limitations. First, although a large number of colorectal polyps were included for analysis in this study, it was a study performed in single hospital. Second, only positive HM and VM status was evaluated in this study. Systematic evaluation of recurrence and metastasis after polyp resection could not be performed because most of colorectal polyps with positive HM and VM underwent additional ER or surgery and long-term follow-up was unavailable. Further studies are required to analyze whether recurrence differs among different endoscopic methods. Third, in our retrospective study, selection criteria for HSP, EMR or ESD for colorectal polyps may differ slightly among different endoscopists. Percent of sessile polyps or polyps sized more than $2 \mathrm{~cm}$ also differed among polyps with different ER methods due to difficulty of en bloc EMR or HSP resection to sessile polyps or large polyps. This contributed to the selection bias and could not be clarified in this study. To a certain extent, analysis based on realworld clinical practice may generalize our results. And a prospective study needs to be performed to eliminate this bias. Fourth, some pathology related information such as the median resection depth, could not be collected and requires prospective study. Fifth, we were unable to investigate whether $\mathrm{pT} 1 \mathrm{a}$ or $\mathrm{pT} 1 \mathrm{~b}$ components contributed to the higher risk of positive VM as compared to AAs in polyps undergoing HSP due to the small number of cases. Further study involving larger number of lesions is needed for investigation.

Taken together, choice of endoscopic resection methods based on size and morphology of the tumor in guarantee of en bloc resection for treatment of pTis carcinomas was rational. ESD was preferred over EMR for pT1a carcinomas with lower rate of positive VM.

\section{Abbreviations}

ECRC: Early colorectal cancer; AA: Advanced adenoma; ER: Endoscopic resection; HSP: Hot snare polypectomy; EMR: Endoscopic mucosal resection; ESD: Endoscopic submucosal dissection; VM: Vertical margin; HM: Horizontal margin.

\section{Acknowledgements}

Nothing to declare. 


\section{Authors' contributions}

Conception and design of the study: QW Z, ZZ G and XB L; Generation, collection, assembly, analysis and/or interpretation of data: QW Z, ZH D and YJ G; Drafting or revision of the manuscript: QW Z, ZH D, XY W, ZZ G and XB L; Approval of the final version of the manuscript: QW Z, ZH D, XYW, YJ G, ZZ G and $X B \mathrm{~L}$. All authors have read and approved the manuscript.

\section{Funding}

This work was supported by grants from the National Natural Science Foundation of China (No. 81670505, 81772519), the Shanghai Municipal Education Commission: Gaofeng Clinical Medicine grant support (No. DLY201501), the three-year action plan for Shin Kang of Shanghai (No. 16CR3113B), Cross medical research fund of translational medicine, Shanghai Jiao Tong University (No. ZH2018ZDA06), Shanghai Municipal Key Clinical Specialty (No. shslczdzk05902), and Shanghai Municipal Commission of Health and Family Planning (No. 2018YQ29). The funding source had no role in the study design, data collection, data analysis, data interpretation, or writing of the report.

\section{Availability of data and materials}

The datasets generated and/or analysed during the current study are not publicly available due personal information involved but are available from the corresponding author on reasonable request.

\section{Declarations}

\section{Ethics approval and consent to participate}

The study protocol was approved by the Ethics Committee of the Renji Hospital, written informed consent was obtained from each patient before performing endoscopic resection.

\section{Consent for publication}

Not applicable.

\section{Competing interests}

Authors had nothing to declare.

Received: 20 May 2020 Accepted: 24 December 2021

Published online: 29 January 2022

\section{References}

1. Gupta AK, Melton LJ 3rd, Petersen GM, Timmons $L$, Vege SS, Harmsen WS, et al. Changing trends in the incidence, stage, survival, and screendetection of colorectal cancer: a population-based study. Clin Gastroenterol Hepatol. 2005:3:150-8.

2. Amri R, Bordeianou LG, Sylla P, Berger DL. Impact of screening colonoscopy on outcomes in colon cancer surgery. JAMA Surg. 2013;148:747-54.

3. Kudo S. Endoscopic mucosal resection of flat and depressed types of early colorectal cancer. Endoscopy. 1993;25:455-61.

4. Tanaka S, Oka S, Kaneko I, Hirata M, Mouri R, Kanao H, et al. Endoscopic submucosal dissection for colorectal neoplasia: possibility of standardization. Gastrointest Endosc. 2007;66:100-7.

5. Ikematsu H, Yoda Y, Matsuda T, Yamaguchi Y, Hotta K, Kobayashi N, et al. Long-term outcomes after resection for submucosal invasive colorectal cancers. Gastroenterology. 2013;144(551-559):quiz e514.

6. Labianca R, Nordlinger B, Beretta GD, Mosconi S, Mandala M, Cervantes A et al. Early colon cancer: ESMO clinical practice guidelines for diagnosis, treatment and follow-up. Ann Oncol. 2013;24(Suppl 6):vi64-72.

7. Bond $\mathrm{JH}$. Polyp guideline: diagnosis, treatment, and surveillance for patients with colorectal polyps. Practice parameters Committee of the American College of gastroenterology. Am J Gastroenterol. 2000;95:3053-63.

8. Hashiguchi Y, Muro K, Saito Y, Ito Y, Ajioka Y, Hamaguchi T, et al. Japanese Society for Cancer of the Colon and Rectum (JSCCR) guidelines 2019 for the treatment of colorectal cancer. Int J Clin Oncol. 2020;25:1-42.

9. Saitoh Y, Inaba Y, Sasaki T, Sugiyama R, Sukegawa R, Fujiya M. Management of colorectal T1 carcinoma treated by endoscopic resection. Digest Endosc. 2016;28:324-9.
10. Tanaka S, Oka S, Chayama K. Colorectal endoscopic submucosal dissection: present status and future perspective, including its differentiation from endoscopic mucosal resection. J Gastroenterol. 2008;43:641-51.

11. Bosman FT, Carneiro F, Hruban RH, Theise ND. WHO classification of tumours of the digestive system: World Health Organization; 2010.

12. Sugihara K. Japanese Society for Cancer of the Colon and Rectum: Japanese classification of colorectal carcinoma. 2nd English edition Tokyo: Kanehara; 2009. p. 27-8.

13. Compton CC, Fielding LP, Burgart L, Conley B, Cooper HS, Hamilton SR, et al. Prognostic factors in colorectal cancer. College of American Pathologists Consensus Statement 1999. Arch Pathol Lab Med. 2000;124:979-94.

14. Gellad ZF, Voils Cl, Lin L, Provenzale D. Clinical practice variation in the management of diminutive colorectal polyps: results of a national survey of gastroenterologists. Am J Gastroenterol. 2013;108:873-8.

15. Singh N, Harrison M, Rex DK. A survey of colonoscopic polypectomy practices among clinical gastroenterologists. Gastrointest Endosc. 2004;60:414-8.

16. Suzuki S, Gotoda T, Kusano C, Ikehara H, Sugita A, Yamauchi M, et al. Width and depth of resection for small colorectal polyps: hot versus cold snare polypectomy. Gastrointest Endosc. 2018;87:1095-103.

17. Sakamoto T, Matsuda T, Nakajima T, Saito Y. Clinicopathological features of colorectal polyps: evaluation of the 'predict, resect and discard'strategies. Colorect Dis. 2013;15:e295-300.

18. Mizutani T, Tanaka M, Eba J, Mizusawa J, Fukuda H, Hanaoka N, et al. A phase III study of oral steroid administration versus local steroid injection therapy for the prevention of esophageal stricture after endoscopic submucosal dissection (JCOG1217, steroid EESD P3). Jpn J Clin Oncol. 2015;45:1087-90

19. Ito A, Suga T, Ota H, Tateiwa N, Matsumoto A, Tanaka E. Resection depth and layer of cold snare polypectomy versus endoscopic mucosal resection. J Gastroenterol. 2018:53:1171-8.

20. Zhang QW, Teng LM, Zhang XT, Zhang JJ, Zhou Y, Zhou ZR, et al. Narrowband imaging in the diagnosis of deep submucosal colorectal cancers: a systematic review and meta-analysis. Endoscopy. 2017:49:564-80.

\section{Publisher's Note}

Springer Nature remains neutral with regard to jurisdictional claims in published maps and institutional affiliations.
Ready to submit your research? Choose BMC and benefit from:

- fast, convenient online submission

- thorough peer review by experienced researchers in your field

- rapid publication on acceptance

- support for research data, including large and complex data types

- gold Open Access which fosters wider collaboration and increased citations

- maximum visibility for your research: over $100 \mathrm{M}$ website views per year

At BMC, research is always in progress.

Learn more biomedcentral.com/submissions 